\title{
Free and Inexpensive Materials on Computing in Teaching and Learning Activities
}

\author{
AN INFORMAL APPRAISAL
}

\section{INTRODUCTION}

This is an excerpt from a document intended for persons wishing to establish inexpensively a library of reference materials and periodicals on use of computing in teaching and learning activities. The primary intention is to be of service to colleges and universities participating in Project EXTEND in the state of Michigan or elsewhere. However, the information has proved useful to other sectors of education and training as well, e.g. high schools and industrial training.

The information is drawn from a variety of sources, in particular the Guide to Information Sources from Project CLUE (see entry in Reference Materials section). Although many of these entries have been checked against current issues of the periodicals or reference works, we do not mean to assure that the materials are still available at the price indicated, or even available at all. Furthermore, additional sources not known to us at the date of this current revision (April 1975) may be equally helpful. We would appreciate being informed of additional information to add to this advisory note.

The first section lists periodicals available free or by subscription of $\$ 8$ or less per year. Most of the annotations are informal opinion; other views should be considered if one is seeking critical comment on the periodicals. Furthermore, other periodicals should be considered without regard to cost because they may add significantly to the collection of information (see the Project CLUE Guide to Information Sources for a longer listing). The entire set of 20 periodicals listed here would cost on $1 y \mathbf{3 4}$ per year.

The second section lists reference materials avallable for $\$ 10$ or less. The list could be very much longer but a selection has been made in order to keep the total cost of such a library low. Another way to reduce the cost is to acquire some reference works in microfiche format if reading equipment is available. Indeed, some

${ }^{x}$ Prepared for the Project EXTEND Information Exchange. Excerpted by the editors of System. 
of the very expensive books are available for a few dollar: in microfiche.

The third section summarizes some key projects which any newcomer to the field should know about. Some of them main. tain mailing lists and distribute useful technical reports and other documents without charge. This list also could be made much longer; a selection has been made to be of maximum assistance to persons beginning work on instructional use of computing in colleges and universities.

The user of this guide cannot be reminded too often to look to other sources for information. Sometimes a commercial publication priced at more than the limit set for this guide is well worth the additional money. Also other sources may lead to yet further hints about inexpensive materials.

\section{PERIODICALS}

ACM SIGCUE Bulletin. Four issues per year; $\$ 4$ for members of ACM; \$6 otherwise. Editor: Joyce Statz, Computer Science, Bowling Green State University, Bowling Green, $\mathrm{OH}$ 43403. Membership: ACM Headquarters, SIGCUE, Association for Computing Machinery, P.O. Box 12105, New York, NY 10249 .

This bulletin is distributed to about 1,400 members of the Special Interest Group on Computer Uses in Education (SIGCUE) of the Association for Computing Machinery (ACM). It is probably the single best source for computers in college teaching and learning, including a calendar, news, brief technical reports, book reviews and comments on conferences.

CALCULI. Six issues per year; no charge for current issues. Back issues and indices to pages $1-100$ and $101-202$ are available for $\$ 7.50$ ( $\$ 8.50$ if billing is required). Editor: Steven V.F. Waite, Classics, Dartmouth College, Hanover, NH 03775 .

Each number is four to eight pages, pre-punched for easy addition to a binder in which information about computers in classics and news of meetings and a blbilography are accumulated. The periodical is published by Dartmouth college with support from the American Philological Association, and its success indicates how an institution can provide a very helpful service to a discipline at very low cost.

CAPRICE: Computer-Assisted and Programmed Instruction in Communications and Education. Four issues per year; no 
charge. Editor: Dawn Cizmar, office of Instructional Resources, 450 Library East, University of Florida, Gainesvilie, FL.

CAPRICE carries news of current research in computer-assisted and programmed instruction with particular emphasis on communications and education. The newsletter also carries a conference calendar and news about journals.

Computer Education. Three journals per year; $\$ 5$. Editors: Peter Lambert, National Computing Centre, and C.N. Dally. Sandhurst School. Subscriptions: Mrs. P. Jackson, The Computer Education Group Treasurer, North Staffordshire Polytechnic Computer Centre, Blackheath Lane, Stafford, England.

The Computer Education Group, an affiliate of the British Computer society, does an excellent job getting information to teachers and others interested in computers in school. Each issue includes ideas for classroom use, reports on activities in various schools, news of new developments, and information about conferences and reports particular to the United Kingdom. Ideas for individual and group activities relating to computing studies and computer literacy transfer readily across the Atlantic.

Creative Computing. Six issues per year; $\$ 8 ; \$ 6$ for students or groups; $\$ 15$ for institutions. Editor: David H. Ahl, Ideametrics, Box 789-M, Morristown, NJ 07960 .

A very new publication having only a few issues as of this date. The previous work of the editor on similar publications is very good. The style is very light, and perhaps more for elementary and secondary schools than for colleges and universities, although half the editors are in higher education. One can expect articles pertinent to higher education from editors A. Kent Morton, Karl L. Zinn, Alfred Bork and others.

EDU. Six issues per year; no charge. Editor: Sally $R$. Bower, Digital Equipment Corporation, 146 Main Street, Maynard, MA 01754 .

This newsletter is primarily for users of educational computing systems marketed by Digital, but its interesting reports, news and suggested activities are useful to anyone. Although much of the writing may be directed at secondary school users, many of the ideas apply to any level. 
EDUCOM Bulletin. Four issues per year; free to faculty of member institutions; $\$ 5$ to educators and students; $\$ 10$ to others. Subscriptions: EDUCOM, Box 364, Rosedale Road, Princeton, NJ 08540 .

News on computer and information systems in higher education is covered in each issue with particular attention to the activities of EDUCOM (Interuniversity Communications Council). Although very helpful for general information and pointers to specific sources, this periodical does not usually contain specific ideas for computer use.

HP Educational Users Group Newsletter. About eight issues per year; no charge for users of HP equipment; $\$ 6$ otherwise. Carol Scheifele, 11000 wolfe Road, Cupertino, CA 95014 .

This newsletter is primarily for users of educational computing systems marketed by HP (Hewlett-Packard). Similar to EDU, it offers helpful information and ideas to many readers regardless of the computing system they use. Both HP and Digital are providing a significant service to education as each one builds its share of a growing market.

Information Resources. About four issues per year; no charge. Editor: Maxine Sitts. Editorial officers: ERIC clearinghouse on Information Resources, Stanford Center for Research and Development in Teaching, Stanford University, stanford, CA 94305.

This clearinghouse, one of about a dozen on various topics, is the most likely to carry information about computers in teaching and learning. Almost every issue of its newsletter has some note on reports dealing with computer-assisted instruction or sometimes other kinds of computer use. The various clearinghouses are supported by the office of Education to collect, review and abstract publications and documents, and to index them for inclusion in a computer-accessed data base. A few free materials are available dealing with various phases of information resources.

ON-LINE: A Newsletter on Educational Use of Computers Among Michigan Colleges and Universites. Six issues per year; no charge to persons in colleges and universities in Michigan, and other institutions cooperating in the information exchange; \$4 otherwise. Editor: Karl L. Zinn, U-M CRLT, 109 E. Madison St., Ann Arbor, MI 48104.

This newsletter informs faculty and administrators about computers in teaching and learning activities, 
focusing on matters of interest within Michigan and neighboring states and provinces. Each issue carries brief reports, conference information, news, reviews and comments. A special issue each summer reports on an annual Conference on Instructional computing in Michigan. Probably this publication is not very helpful outside the Midwest; in any case, the SIGCUE Bulletin provides national scope at the same price.

Peoples Computer Newsletter. Five issues per year; $\$ 5$. Editor: Bob Albrecht, People's Computer Company, P.0. Box 310, Menlo Park, CA 94025.

In newspaper format, this periodical carries much information, emphasizing ideas and activities immediately useful in a secondary school classroom using computing. Many games, problems and other challenges are put forth in its pages. Back issues are a bargain.

PLANIT Newsletter. Four to six issues per year; $\$ 4$ to individual subscribers in the USA; $\$ 5$ to individual subscriber outside the USA; $\$ 10$ for an institutional subscription. Editor: Lyle B. Smith, PLANIT Users Group, SCIP at SLAC, Bin 97, stanford, CA 94305.

Dedicated entirely to information about the authoring language PLANIT, this periodical would not be of much interest except to users and potential users of that language. It provides information about meetings, new instaliations, and program exchange.

THE Journal (Technological Horizons in Education). Eleven issues per year: no charge to persons who qualify (e.g. administrators and department chairmen); $\$ 15$ otherwise. Editor: John F. Martell, Information Synergy, Inc., P.O. Box 992, Acton, MA 01720 .

This periodical covers a range of technologies (video, film and specialized print materials as well as computers) with emphasis on future developments. Every one of the first five issues has had two or more articles on computers in teaching.

UCODI Newsletter. About four issues per year; no charge. Services and subscriptions: Centre Imago - UCODI Department. Celestijnenlaan, 200-C, 3030 Heverlee, Belgium.

The Centre for Educational Research and Innovation (CERI) of OECD (in Paris) established a documentation center for computers in education. This newsletter conveys information about its activities and resources. 


\section{REFERENCE MATERIALS}

Computers in Humanistic Research: Readings and Perspectives. Englewood Cliffs: Prentice-Ha11, Inc., 1967. \$7.95.

A collection of papers from six regional conferences in the United states dealing with the role of the computer in humanistic research. Contents include surveys of the varied uses of the computer in anthropology, archaeology, history, political science, language and literature, and musicology, as well as discussions of the special problems confronting a humanist scholar dealing with computer research. Most of the articles are written in non-technical language and are comprehensible to lay readers.

Holtzman, Wayne H., ed. Computer-Assisted Instruction, Testing and Guidance. New York: Harper \& Row, 1970. \$10

The twenty papers in this book were prepared for a conference at the University of Texas at Austin in october, 1968, organized by the Social Science Research Council and the College Entrance Examination Board. They encompass a wide range of subject areas including: system and instructional design, learning strategies, complex man-machine systems, and computer guidance and counseling. Although a number of the papers are technical and require some expertise in computer technology, the critical discussions are of general interest and are comprehensible to a novice in the field. This book is a useful supplement for a course on educational technology, or for psychological aspects of computers in education.

Levien, Roger. Computers in Instruction: Their Future for Higher Education. Proceedings of a Conference. Rand Corporation, October 1970. Report Number R-718-NSF/CCOM/RC. $\$ 7.00$.

About 25 contributions were arranged to consider computer capabilities and costs, sources of service, sources of instructional materials, and the tmpact on higher education and policy recommendations. This proceedings is a very helpful collection of statements about computers in higher education. The book is available from the Rand Corporation, 1700 Main Street, Santa Monica, CA.

Moursund, David, Mike Dunlap, et. al, Computers in Education Resource Handbook. University of Oregon: Department of Computer Science, 1973. Approximately 500 pp. $\$ 10.80$.

A group of persons involved in studying, teaching 
and using computers in education assembled a resource handbook during sumer 1973. The effort was motivated by a series of NSF-supported institutes in computer science run by Moursund and a course on computers in education taught by Dunlap. The handbook covers education about, with and by computers and includes additional sections on facilities, training, research and sources. It is currently being revised for reprinting and is available from the Department of Computer Science, University of Oregon, Eugene, OR 97403 .

Nelson, Theodor. Computer Lib/Dream Machines. Hugo's Book Service, Box 2622, Chicago, IL 60690.\$7.00.

This book is an unusual resource. From the front side (Computer Lib), it provides a course in computer applications and appreciation, including more anecdotes and inside stories than one is likely to find in the repertoire of any single, exceptional lecturer on the subject. From the "filp side" (Dream Machines), the book offers a look into the future, challenging (potential) computer professionals to make something of value out of the powerful resources becoming available.

Organization for Economic Cooperation and Development. Seminar on the Use of Computers in Higher Education, Portland, Oregon, 1970. Paris: Organization for Economic Cooperation and Development (OECD), 1971.

This seminar was organized by the U.S. Office of Education and the Northwest Regional Educational Laboratory with a subsidy from the National Science Foundation; it was attended by experts from Europe, the Far East, and the United States. The proceedings contain an overview of current activities in computers and instruction along with some recommendations for internationalizing and exchanging research and experiences. Copy is available without charge from OECD/CERI at 2 rue Andre-Pascal, Paris 75700 , France.

Proceedings of a Conference on Computers in the Undergraduate Curricula. 1970 through 1974. CCuC Proceedings, University of Iowa, Computer Center, LCM, Iowa City, IA 52242 . \$10 each.

The Conference on Computers in the Undergraduate Cuxricula has become an annual event. There are approximately 80 papers in each collection describing a wide variety of ideas and techniques for improving the teaching of traditional subjects through adjunctive use of the computer. 
United Nations Educational, Scientific, and Cultural organization. Consultation on Computer-Assisted Instruction for Developing Countries. Final Report. Paris: UNEsco, 1970 .

In response to a number of inquirles about computers in instruction from developing countries, UNEsco called together experts in this field for a consultation session in Paris, March 16-18, 1970. Experts from around the world were asked to comment on fourteen important questions prepared by the UNESCO secretariat and to consider a large-scale CAI project in Spain. This report is a good international review of the current state of computers in education and includes guidelines. It is intended to be helpful to developing countries. Copy is available without charge from E.R. Prabhakar, ESM/ MMT, UNESCO, Place Fontenoy, Paris 75700, France.

Zinn, Karl L. An Evaluative Review of Uses of Computers in Instruction. Ann Arbor: Center for Research on Learning and Teaching, University of Michigan, December 1970. $\$ 5$.

The final report of Project CLUE (Computer Learning under Evaluation) provides a current description of activities in this field. Appendix A of Volume I (Guide to Information Sources) is particularly useful for tracking down information about computer uses and technology. Available from ERIC, microfiche; multilith copy from Zinn, 109 E. Madison, Ann Arbor, MI 48104 .

SOME KEY PROJECTS

Engineers at the University of Illinols, Urbana, have designed a computing system (PLATO IV) especially for effective and efficient use in education. It is a large system intended to provide instructional computing to over 1,000 simultaneous users throughout the University and also a number of other colleges and schools in Illinois. The design includes notable advances in the technology for display and special arrangements for efficient communications through broadband channels of the telephone system. University faculty are authoring computer-based curriculum materials. The development work has been of considerable interest to universities and school systems in other states. Some other institutions (e.g. universities in Indiana, Iowa and Florida) are exploring the need and requirements for installation of PLATO IV systems. A list of available documents can be obtained from CERL, University of Illinois, Urbana, IL 61801 .

TICCIT (Technology for Interactive Computer Controlled Informational Television) is a name given to systems being developed by Mitre Corporation in Melean, Virginia. The first version of an instructional system 18 designed 
especially for use in a small college. It is based on a medium-sized computer system and video technology to obtain low-cost operation with about 100 simultaneous users. The hardware and software design has been coordinated with the development of instructional materials which are very carefully prepared according to certain rules of effective instruction. The first set of materials are being prepared by instructional design teams at Brigham Young University in Utah to provide basic remedial instruction in mathematical and language skills at small colleges. Technical reports are available from ICUE, Brigham Young University, Provo UT $\mathbf{8 4 6 0 1}$ and a system overview from MITRE Corporation, Westgate Research, McLean, VA 22101.

Stanford University operates a computing system which distributes instructional computing to a number of centers throughout the country. It is a large-scale, service operation at present, depending on long distance telephone communications. Satellite computer systems control clusters of terminals at remote centers usually associated with elementary school demonstration projects and special education institutions. The service operation is conducted in parallel with an extensive program of research and development at the Institute for Mathematical studies in the Social Sciences, Stanford University. Curriculum materials have been prepared for young children (elementary school), learners with special difficulties (for example, the deaf) and certain university courses (especially second language learning). A list of reports is available from IMSSs, Ventura Hall, Stanford, CA 94305.

Dartmouth College has demonstrated the ability of an institution of higher education to make computing as available to students as the library or science laboratory. Essentially all students at Dartmouth College learn about computing and are expected to make effective use of the computer throughout their four years of study. All disciplines of study at the college have been affected, including language instruction, history, and art as well as the expected areas of sciences and mathematics. The same time-sharing computing system is used by a number of other colleges and secondary schools within convenient telephone distance of Dartmouth College, and has been duplicated at other institutions and in commercial timesharing services.

The University of California at Irvine hosts the Physics Computer Development project. A number of simulations and dialogues (typically discussions of problem solutions and proofs) have been prepared for use in college physics teaching, and some in other disciplines as well (e.g. chemistry, mathematics and biology). The project uses the general purpose computers available on campus, and the dialogues are avallable to all students who know 
how to access the computers. Faculty and students at other campuses in the University of California system also use the materials, and some are authoring new dialogues. A list of available documents can be obtained from PCDP, Physics, University of California, Irvine, CA 92664.

A consortium of regional computing services is exploring means for exchange of computer-based instructional computer programs and related curriculum materials. Guidelines have been prepared for preparation and documentation of programs to make them less costly to implement on another computer. Another set of guidelines is for related written materials necessary for effective use of the computer programs in another academic setting (student guide, teacher manual, etc.). A list of documents, programs under review and a newsletter are available from CONDUIT, Box 388, University of Iowa, Iowa City, IA 52240 .

Many colleges and universities in North America are pursuing interesting developmental projects and worthwhile operations with computers in education. A small but significant percent of elementary and secondary schools in North America are providing computing experiences for al1 students in science and mathematics classes, and to some extent in social sciences and humanities. The four projects mentioned above have large budgets or visible impact, but they represent a small portion of the total instructional computing activity.

Considerable excellence in instructional computing is also apparent in institutions and special projects in Europe and Japan. Often these are pursued with considerably less financial investment than the most visible projects in the United states.

Project EXTEND

Part of a Development Program on

Information Processing Facilities as a Basis for Learning Environments

Center for Research on Learning and Teaching

109 East Madison Street

Ann Arbor, Michigan 48104

Staff: Karl L. Zinn, Director (313/763-4410)

Diann Bradarich, Assistant Editor (313/763-0158)

Project EXTEND's major goal is to expand effective use of computing in the academic programs of Michigan colleges and universities. The first phase was supported by Exxon Education Foundation during 1971-73. It included gathering computer-based learning alds from various sources, documenting them for more convenient use, and advising users 
of computing in a sample of colleges and universities in the state.

A major product of Project EXTEND has been a set of introductory and reference materials for the initiation of computer applications in college courses and independent study programs. The materials are intended to reduce the need for extensive consultation with computer experts. The goal is to make computing resources more relevant for undergraduate students and teachers and more usable for new and infrequent computer users.

Project EXTEND continues to function as a point of exchange for computer programs, ideas and experiences from schools of all sizes in the state. The newsletter ONLINE is distributed to over 1,000 subscribers six times a year. An annual conference on Instructional Computing in Michigan is held in the spring of each year. Assistance is provided for publication of reports on effective use of computers for instruction in Michigan colleges and universities.

The MERIT Computer Network. EXTEND has built upon the considerable resources brought together by MERIT, a cooperative venture among the three largest universities in the state, to develop an educational computer network connecting the existing central computing facilities of MSU, U-M, and WSU. Engineering development of the network was begun in 1969 and full operations were first demonstrated in 1972. The MERIT Network provides individual users acces to a richer variety of computing resources in Michigan than would otherwise be possible.

The Center for Research on Learning and Teaching. Project EXTEND is housed at a University of Michigan resource center which has been exploring computer applications within the college learning environment for some time. The center has given particular attention to developments which can be applied to student use of computing in various disciplines, and its staff has advised many University of Michigan professors on effective use of computers in the instructional process.

Selected Documents from CRLT:

"Computer Assistance with Learning and Teaching." Proposed text for Encyclopedia of Computer Science. Anthony Ralston, Ed. New York: Mason and Lipscomb, in preparation. Preprint for comment.

"Free and Inexpensive Materials on Computers and Education." Ann Arbor: Center for Research on Learning and Teaching, December 1974. Single copy distributed without charge; $\$ 1$ per 8 copies. (12 pages)

center for Research on Learning and Teaching University of Michigan 